\title{
FILM AS DATABASE: A VISUAL ANALYSIS OF 2001:A SPACE ODYSSEY
}

\author{
Peter Maloney \\ Course Director, Graduate Diploma Motion Graphics \\ Chelsea College of Art and Design \\ 16 John Islip Street \\ London \\ SW1P 4JU \\ p.maloney@chelsea.arts.ac.uk \\ http://www.chelsea.arts.ac.uk
}

This paper reports on research that explores new possibilities for experiencing film as a digital database. The way we access, interact with and experience film is changed with new digital tools and initial visual experiments towards the design of a graphical user interface respond to this change. The film 2001:A Space Odyssey by Stanley Kubrick is the focus for the research. It is essentially a visual film with an expanded context of critical writing and archived material. Two visual outcomes that map the use of red within scenes of the film will be demonstrated in order to critique and review the film in its new context.

\section{INTRODUCTION}

This project seeks, through experiments with computer visualisation techniques, to map film as an expanded database with the purpose of generating new interpretations of it. The aim of the project is to develop a method for the mapping and visual analysis of time based media. The report describes the context, methodology and outcomes from practical visual experiments conducted to test this proposal.

\section{CONTEXT}

The project acknowledges that the way we experience cultural artefacts such as film has changed through the widespread access to new digital tools for production, consumption and distribution. The fact that increasingly these artefacts are digital from conception to completion means they are quantifiable and therefore open to exploration and analysis as digital databases. This research is undertaken to test new ways of visualising and analysing film and moving image as a form of interactive and reflexive interface, with the possibility of making it searchable and viewable in its wider critical and historical context.

\section{FOCUS}

2001: A Space Odyssey, by Stanley Kubrick is the focus for the visual experiments. Kubrick was an obsessive researcher and archivist meaning that a substantial amount of material from every stage of the writing, making and distribution of the film survives. The recently opened Kubrick Archive at the London College of has been of great use for the project providing access to materials such as scripts and the Sasco cards used by Kubrick to plan the production schedule. The film has inspired a great deal of associated critical writing concerning among other things; its production processes and special effects, the meanings within the film, its unconventional open ended form and its essentially visual approach to narrative. The expanded context for the film offers great 
potential for visual analysis, with possibilities for the mapping of the film alongside its critical and historical contexts.

2001 is recognised now by many as a classic film. It is however unconventional in its narrative form. There is no dialogue for the first 25 minutes and in fact, here is no dialogue for one and a half hours of the two hour twenty minute film. Stanley Kubrick, the director, famously said of the film: "I don't like to talk about 2001 much because its essentially a non-verbal experience. Less than half the film has dialogue. I think clearly there's a basic problem with people who are not paying attention with their eyes ... Those who wont believe their eyes wont be able to appreciate this film." [1]

\section{METHODOLOGY}

In order to begin to think about conducting a visual analysis of a film, it was necessary to consider the basic visual elements that make up the film image. A method for the disassembly of film was developed in order to represent it as modular elements for subsequent mapping. Secondly, 2001: A Space Odyssey was considered specifically in relation to the Archive and the body of critical writing in order to find specific visual themes that were of interest and that could be analysed visually for review.

The method used to map the film is inspired by and adapted from historical precedents in the visualising of narratives in space and time. In order to break down or disassemble film into modular elements, an idea of reverse storyboarding was tested. The constructivist approaches to film production and planning taken by Sergei Eisenstein [2] were examined as a starting point for this process. Of particular interest was the storyboard accompanying the film 'Alexander Nevsky' from 1938. Here Eisenstein breaks the film down into its basic elements, visualising in sequence aspects of the film such as:

- Picture Frames: Screen compositions taken from each shot

- Musical Phrases and Musical Score

- Film Length (in Minutes)

- Diagrams of pictorial composition

- Diagrams of Movement: position and movement of characters

\section{Narratives of space and time}

In the chapter 'Narratives of Space and Time' Edward Tufte [3] states that information displays that deal with the subject of mapping narratives in space and time combine two familiar design forms, namely, the map and the time series. His first example to demonstrate this is pertinent to the narrative within 2001, showing the drawings made by Galileo as he began plotting the position of Jupiter and its moons.

Tufte describes how Galileo made periodic observations through his telescope and noticed that the 'starlets' as he called them, appeared to be moving, as he had noted the alterations in their arrangement. The plotting of the positions of the elements over a period of days and weeks revealed how the four satellites revolved around Jupiter. In 1613 Galileo plotted longer time series and Cassini extended this work in 1668. It was however not until 1988 that the points were joined to form trajectories. It is this simple 
method of plotting points over time that was adapted to generate the subsequent visual analyses.

\section{OUTCOMES}

\section{Mapping 2001: A Space Odyssey}

A colour analysis of the film was generated by averaging out the colours which appear in the film. The resulting images were placed in a grid which can be read from left to right and from top to bottom to give a graphic sense of the films progression, in effect a graphic interface to the film.

In order to consider graphic means of representing the film in relation to its wider critical, contextual and archival contexts the graphic representation of the film was laid out as a linear sequence. In order to test the possibilities for this to represent possibilities for a remixed interface to the film a second visual test shows the film reconfigured in colour and tonal ranges. Visual possibilities for the development of graphic languages to demonstrate the film in relation to related archived or critical material was also proposed. Subsequent visualisations were tested adapting Galileo's method of plotting position over time. Images were drawn to demonstrate the position of the characters Bowman, Poole and HAL within the frame during the Jupiter Mission scene on the Discovery Spacecraft.

This notion of the interface to film had developed from the contemporary context for viewing moving image content. Once film became digital it could be argued that its sense of sequential development was lost. Individual frames on celluloid exist in the context of the filmstrip showing previous and preceding frames within a given sequence. This visualisation of the film acts as an index allowing the potential for nonlinear access. This technique was then further developed to test the possibilities for conducting visual analyses of the film based on specific aspects from the wider critical context to demonstrate how new interpretations of the film could be generated for specialist audiences.

\section{The use of red in 2001: A Space Odyssey}

Stanley Kubrick's use of the colour red in the film is discussed by Walker, Taylor, and Ruchti [4]. They offer a justification and explanation for Kubrick's approach to colour based on the fact that he had started out as a black and white photographer on the Chicago Tribune. They consider 2001 to be his first colour feature as a Director (discounting Spartacus which was a film he did not have full control over, working instead under Kirk Douglas) and describe his use of colour in the film as stark: "White, black and red are its predominant hues, the black of space, the white of the spacecraft and the red glow bathing the crew inside the craft at moments of tension, peril or disaster." [4.1]

They go on to further describe Kubrick's use of red in particular scenes and relate it back to his previous career as a photographer, describing it as being the same red as can be found in the photographers darkroom: "When mutinous HAL has to be subdued, Kubrick irradiates the setting with the colour he himself most enjoyed working in: the infrared light of the photographers darkroom." [4.2] 
It is clear in this scene that red is central to communicating the narrative. The resulting visual analysis of the scene seeks to demonstrate this as a sequential progression. Images were produced that demonstrate the amount of red in each within the frame for a particular sequence. These images were then mapped sequentially in the computer in three dimensions.

Red is also used throughout the film as a stylistic and compositional device, the scarlet red of the curved Olivier Morgue Djinn Chairs contrasts with the hard white of the ship. This use of red as a compositional device is the subject for a second analysis.

\section{CONCLUSION}

The aim of the project in the longer term is to design an interface that can visualise the film as a whole in order to map and review external contextual aspects of the film such as critical writing and elements from the archive. This could be done using a system that allows external elements to be mapped directly to the narrative timeline of the film rather than the chronological timeline of the films production history.

Adapting Eisenstein's methods for storyboarding film led to a method for film's disassembly and subsequent graphic reconstruction. Adapting Galileo's method for mapping space and time resulted in the mapping of data from the film as three dimensional forms. A series of moving image outcomes at this stage demonstrate new visual interpretations of 2001 made possible by the navigation of the resulting virtual film forms.

These resultant maps generate an index for the film, placing us outside of it and giving us an overview that allows us to see where we are, where we have been and where we are going. It allows us to see the past, present and future of the narrative concurrently. The use of critical writing to identify contextual elements of the film has allowed new interpretations of the film through visual analysis. We are able to visually explore Stanley Kubrick's use of Red as both emotive narrative device and compositional tool presenting transferable possibilities for the digital analysis of archival objects and their use by specialist audiences. This project seeks to give a visual form to moving image that reflects its changed contemporary context.

\section{ACKNOWLEDGEMENTS}

Many thanks to all at the Kubrick Archive for their help and support. Particular thanks go to Sarah Mahurter and Richard Daniels. 2001: A Space Odyssey is the focus for the methods of critical comment and review in this research project and all copyright remains with the original authors and owners [5].

\section{References}

[1] AGEL, J: The Making Of Kubrick’s 2001 (p.7) 1970 Signet.

[2] EISENSTEIN, S: The Film Sense (p176) 1947 Harcourt Brace.

[3] TUFTE, E. R: Envisioning Information (p97) 1990 Graphics Press.

[4] WALKER, A, TAYLOR, S, AND RUCHTI, U: Stanley Kubrick Director (p.224) 1999 Norton. 
[4.1] WALKER, A, TAYLOR, S, AND RUCHTI, U: Stanley Kubrick Director (p.224) 1999 Norton.

[4.2] WALKER, A, TAYLOR, S, AND RUCHTI, U: Stanley Kubrick Director (p.224) 1999 Norton.

[5] KUBRICK, S; 2001: A Space Odyssey, 1968 Metro-Goldwyn-Mayer, Warner Bothers, Time Warner Entertainment Inc, Turner Entertainment. (based on the original Screenplay by Stanley Kubrick and Arthur C. Clarke) 